\title{
A Self-Contained Subsea Platform for Acoustic Monitoring of the Environment Around Marine Renewable Energy Devices-Field Deployments at Wave and Tidal Energy Sites in Orkney, Scotland
}

\author{
Benjamin J. Williamson, Philippe Blondel, Eric Armstrong, Paul S. Bell, Chris Hall, \\ James J. Waggitt, and Beth E. Scott
}

\begin{abstract}
The drive towards sustainable energy has seen rapid development of marine renewable energy devices (MREDs). The NERC/Defra collaboration FLOw, Water column and Benthic ECology 4-D (FLOWBEC-4D) is investigating the environmental and ecological effects of installing and operating wave and tidal energy devices. The FLOWBEC sonar platform combines several instruments to record information at a range of physical and multitrophic levels for durations of two weeks to capture an entire spring-neap tidal cycle. An upward-facing multifrequency Simrad EK60 echosounder is synchronized with an upward-facing Imagenex Delta $T$ multibeam sonar. An acoustic Doppler velocimeter (ADV) provides local current measurements and a fluorometer measures chlorophyll (as a proxy for phytoplankton) and turbidity. The platform is self-contained, facilitating rapid deployment and recovery in high-energy sites and flexibility in gathering baseline data. Five 2-week deployments were completed in 2012 and 2013 at wave and tidal energy sites, both in the presence and absence of renewable energy structures at the European Marine Energy Centre (EMEC), Orkney, U.K. Algorithms for target tracking have been designed and compared with concurrent, shore-based seabird observations used to ground truth the acoustic data. The depth preference and interactions of birds, fish schools and marine mammals with MREDs can be tracked to assess whether individual animals face collision risks with tidal stream turbines, and how animals generally interact with MREDs. These results can be used to guide marine spatial planning, device design, licensing and operation, as different device types are tested, as individual devices are scaled up to arrays, and as new sites are considered.
\end{abstract}

Index Terms-Collision risk, environmental monitoring, marine renewable energy, multibeam sonar, seabirds.

Manuscript received August 11, 2014; revised January 21, 2015; accepted February 26, 2015. Date of publication March 24, 2015; date of current version January 11, 2016. This work was supported by the Natural Environment Research Council (NERC) and Defra (under Grants NE/J004308/1, NE/J004200/1, and NE/J004332/1). The work of B. J. Williamson was also supported by a NERC MREKEP Internship. (Corresponding Author: Benjamin J. Williamson).

Associate Editor: D. Simons.

B. J. Williamson is with the Institute of Biological and Environmental Sciences, University of Aberdeen, Aberdeen AB24 2TZ, U.K. and also with the Department of Physics, University of Bath, Bath BA2 7AY, U.K. (e-mail: b.williamson@abdn.ac.uk).

P. Blondel is with the Department of Physics, University of Bath, Bath BA2 7AY, U.K.

E. Armstrong and C. Hall are with Marine Scotland Science, Aberdeen AB11 9DB, U.K.

P. S. Bell is with the National Oceanography Centre, Liverpool L3 5DA, U.K.

J. J. Waggitt and B. E. Scott are with the Institute of Biological and Environmental Sciences, University of Aberdeen, Aberdeen AB24 2TZ, U.K.

Digital Object Identifier 10.1109/JOE.2015.2410851

\section{INTRODUCTION}

\section{A. Environmental Impacts of Marine Renewable Energy} Devices (MREDs)

$\mathbf{T}$ HE drive towards sustainable energy has seen rapid development of marine renewable energy devices (MREDs) and current efforts are focusing on wave and tidal stream turbines [1]-[3]. However, little is known of the environmental and ecological effects of installing and operating these devices [4]. Environmental impacts on the surrounding ecosystems, both above and under water (e.g., fish, marine mammals, seabirds) have been assessed differently, from benign to adverse [5], [6]. The experience gained over the last few years, and around the world, has been summarized in recent reviews, which all highlight the need for more generic modes of assessment [7]-[9]. Workshops involving MRED developers and regulators have also emphasised the need for an improved understanding of the baseline environment [10], stressing that, as each technology is different and greatly influenced by the site location, it is necessary to look for common impacts and easily adaptable technologies.

The NERC/Defra collaboration FLOw, Water column and Benthic ECology 4-D (FLOWBEC-4D) is investigating the potential of both physical and ecological effects of MREDs at test sites in Orkney at the European Marine Energy Centre (EMEC), complemented by work already underway at Strangford Lough [11] and Wave Hub [12]. The project aims to understand how currents, waves and turbulence at tide and wave energy sites may influence the behavior of marine wildlife, how important collision risks might be, and how tide and wave energy devices might alter the behavior of wildlife as different device types are tested, as single devices are scaled up to arrays, and as new sites are considered.

Regulators need to know with a high degree of certainty whether tidal and wave devices will affect the population level of marine species, but measuring population level changes is a long term and large spatial range issue. An approach which can rapidly and accurately identify and quantify any changes in individual behavior within a species, brought about specifically by renewable development, can allow the quantification of what those impacts will be at the population level [13]. 
Currently, foraging efficiency (the capture of prey by a predator) is considered to be the major ecological driver of population dynamics, as it controls both adult and juvenile survival and condition [14], [15]. However, tidal stream technologies in particular introduce the addition of collision risk which could potentially represent a new mortality factor. This could significantly affect the population dynamics of many mobile marine species. However, the vertical habitat preference of both mobile prey (such as pelagic fish) and predators (such as diving seabirds and mammals) is generally not quantified with the degree of spatial and temporal accuracies, and over the long time scales, necessary to assess both foraging behavior and collision risk in these high-energy environments.

Predator-prey interactions vary over temporal and spatial scales [16] requiring data to be captured at a high temporal resolution (several measurements a second, e.g., to record prey pursuit and capture) at a spatial resolution commensurate with target animal sizes (ca. $40 \mathrm{~cm}$ and smaller [17], [18]), but also for entire spring-neap tidal cycles (2-weeks) and within breeding and nonbreeding seasons, to identify similarities or differences that may occur within these temporal ranges. Sampling at different locations within wave and energy sites is also required, to understand the use of a range of benthic and vertical water-column habitats by different species and to assess the effect of the presence/absence of MREDs.

Boat surveys can provide high-resolution survey coverage along specific tracks, but it is not logistically feasible to monitor a high-energy site continuously at high-resolution for an entire 14-day tidal cycle. The effects of wind, waves and tide reduce positional accuracy such that boat surveys cannot monitor small-scale interactions of individual targets at the precise location of the MREDs and the costs of long duration surveys are high. Surface moorings, such as instrumented buoys and surface platforms can reduce cost and increase survey duration, but taking high-resolution measurements of the entire water column and measuring the interactions of wildlife with seabed MREDs is limited because of their inherent instability in these high-energy sites [19], [20]. In the case of both boats and moored surface platforms, there is also the risk of the surface presence and platform noise (in air and under water) affecting the species being studied (e.g., birds, fish, and marine mammals) [21]-[23].

Mounting instruments directly on the MRED of interest provides a stable mounting and simplifies power and data requirements. The interactions of fish with tidal turbines have been imaged using cameras but visibility (turbidity and illumination) limits both the range and survey time of a visual approach [24]. Active lighting will directly affect animals and their behaviors, whereas passive visualization is restricted by the amount of daylight reaching the MRED's depth (future generations of MREDs are now also aiming for deep waters [25]). Acoustic instruments mounted on the MRED are adversely affected by turbulence within a few meters from the MRED itself, which can mask the presence and interactions of wildlife [26]. Conversely, a physically independent platform will allow the instruments to be positioned adjacent to the MRED, looking at it from a short distance, recording the interactions of wildlife and also conducting baseline studies elsewhere under similar conditions, e.g., in an area free from MREDs or prior to MRED installation.
The FLOWBEC project addresses all of these issues by combining data from the deployment of a self-contained, upwardfacing seabed sonar platform [27], [28] with shore-based bird observations, shore-based marine X-band radar surveys of wave and current data and detailed 3-D modeling of the flow and water column. The purpose of this project is both to address the lack of ecological understanding of mobile predator and prey use of high-energy sites and to identify and quantify which type of habitats (depth of water column, speed of tides, etc.) predators predictably use in these areas for foraging. In particular this approach will rapidly provide more certainty on the likelihood of collision risk for highly mobile species such as migrating fish, basking sharks, diving seabirds and marine mammals. Shortterm, highly focused studies such as these are what is currently needed to increase our understanding of what the population level effects may be for different types and sizes of MREDs and arrays. This article aims to present the FLOWBEC subsea platform and its suite of instruments, illustrating the types of measurements now accessible and how they can be analyzed to assess the environmental impacts of MREDs.

\section{THE FLOWBEC PLATFORM AND INSTRUMENTS}

The FLOWBEC upward-facing sonar platform allows the interaction of fish, diving seabirds and marine mammals with MREDs to be imaged, and the acoustic environment to be analyzed. The platform combines an Imagenex 837B Delta $\mathrm{T}$ multibeam sonar $(260 \mathrm{kHz})$, pinging at several frames per second for target tracking, identification and behavioral analysis, synchronized with a Simrad EK60 multifrequency echosounder $(38,120$, and $200 \mathrm{kHz})$, operating at 1 ping per second and used for target identification, abundance estimates, measures of plankton and of the morphology of turbulence (see Fig. 1).

The FLOWBEC subsea frame (shown in Fig. 2) was constructed out of stainless steel, with overall dimensions $3.2 \mathrm{~m}$ long $\times 2.9 \mathrm{~m}$ wide and $0.9 \mathrm{~m}$ high, and weighing approximately $4000 \mathrm{~kg}$ in air and $2500 \mathrm{~kg}$ in water. Careful drag and overturning calculations ensured that the frame would remain stable in the expected waves and tidal currents of the envisaged test sites. The batteries were mounted as low as possible, to maintain a low center of gravity, and drag was minimized by using an open frame design and tubular battery housings. All pressure vessels were specified to a working depth of at least $70 \mathrm{~m}$ to suit the typical installation depth of present and near-future MREDs and arrays. The acoustic transducers were mounted flush in a plate on top of the frame (seen as orange disks in Fig. 2) to minimize turbulence. Netting was used to prevent deployment and recovery bridles from falling into the frame and catching on components.

\section{A. Operational Constraints}

A 14-day survey requirement was established to be able to identify ecological differences throughout the full spring-neap tidal cycle, while sampling continuously to identify trends and behavioral differences across diurnal daylight and semidiurnal ebb-flood tidal cycles. Continuous sampling was required at a temporal resolution of at least 1 sample/second and a spatial resolution of at least 1 meter to capture targets moving at speeds 


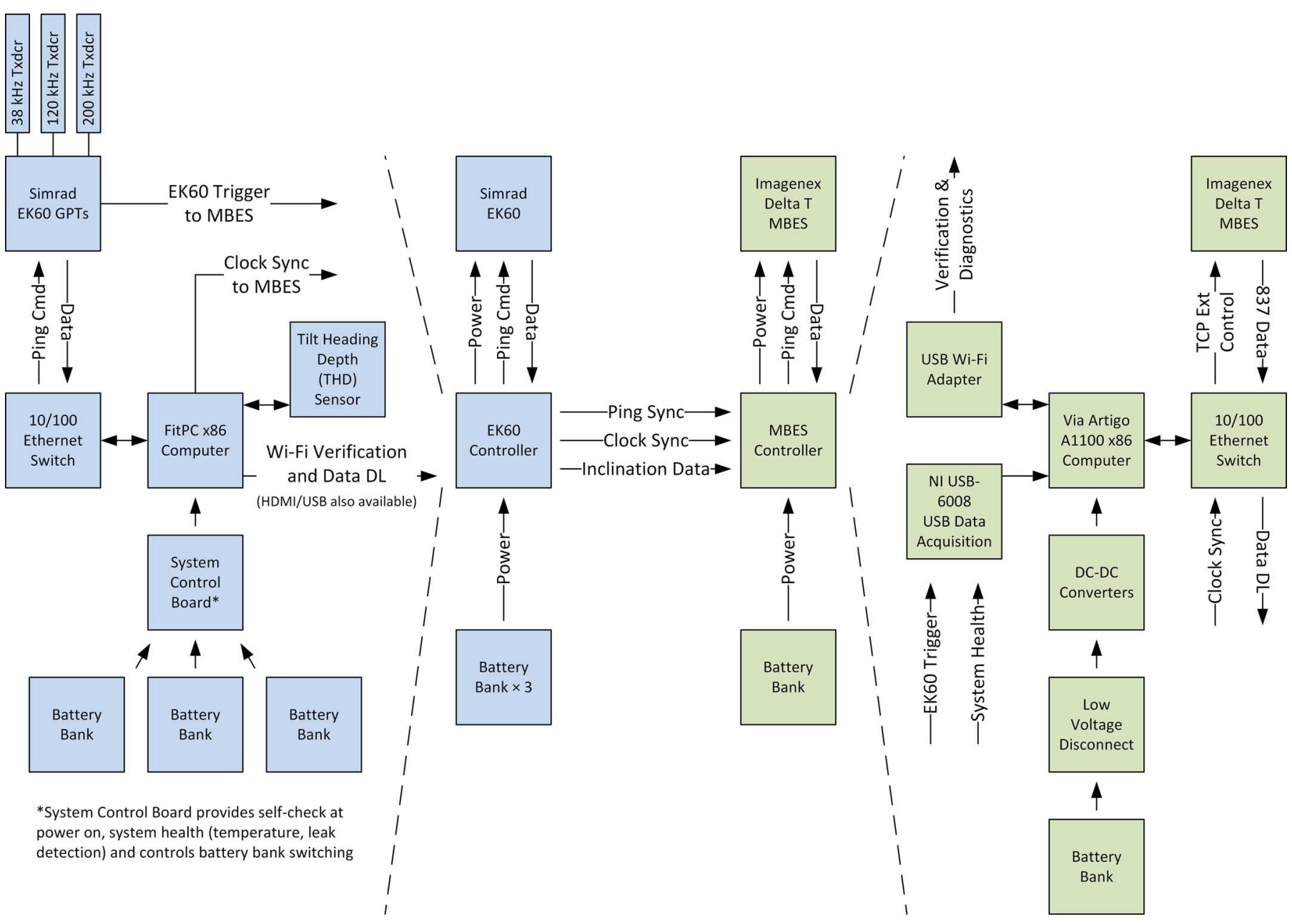

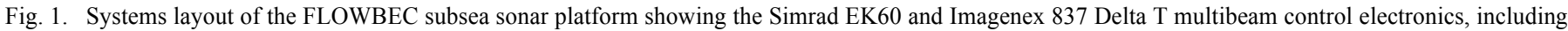
the interfaces between the two systems to ensure data synchronization and to prevent acoustic interference (GPT $=$ General Purpose Transceiver).

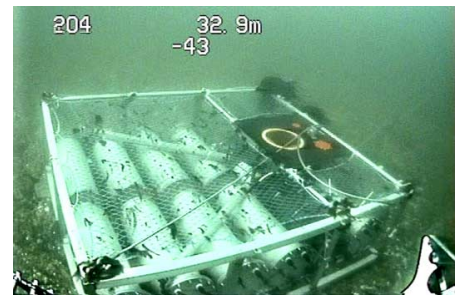

Fig. 2. FLOWBEC subsea frame deployed on the seabed in $33 \mathrm{~m}$ of water at the EMEC tidal energy test site. The image is taken from an ROV during recovery of the frame-the recovery bridles can be seen now laying across the frame prior to being lifted. This image was taken during the first deployment, (2012), before a rigid platform was added for the ROV to land on, to aid hooking the recovery bridle.

of up to $5 \mathrm{~m} / \mathrm{s}$ throughout the entire water column. Multitarget tracking was required to capture the interactions of wildlife with MREDs, predator-prey interactions and how these might be affected by MREDs. The requirement for multifrequency acoustic response to be synchronized with multitarget-tracking multibeam sonar was also established to aid target identification.

\section{B. Power Supply}

Twenty 12-V 220-Ah sealed lead-acid batteries were fitted to the frame in 10 stainless steel tubular housings to provide power for the 14-day deployment, as shown in Fig. 2. Each housing contains two batteries with individual per-battery low-current output connectors and individual per-battery high-current charge connectors, together with vent plugs to allow recharging of the batteries without removal from the housings. The batteries can be recharged and data downloaded in a 24-h service period, to allow immediate redeployment at slack tide the following day during neap tides, to capture the following spring-neap tidal cycle.

Five batteries were used to power the multibeam system. The remaining fifteen were used to power the EK60, arranged in three banks of 5 and used sequentially. Continual monitoring of battery voltage throughout a survey, coupled with low-voltage cutouts, was used to protect the batteries from deep-discharge. DC-DC converters were used to provide the various voltages required by each instrument.

\section{Sonar}

The sonar platform consists of a $260-\mathrm{kHz}$ Imagenex $837 \mathrm{~B}$ Delta $\mathrm{T}$ multibeam echosounder (MBES) interfaced to a 38-, 120- and 200-kHz Simrad EK60 split-beam echosounder (Fig. 1). Each system has its own power supply, instrumentation 


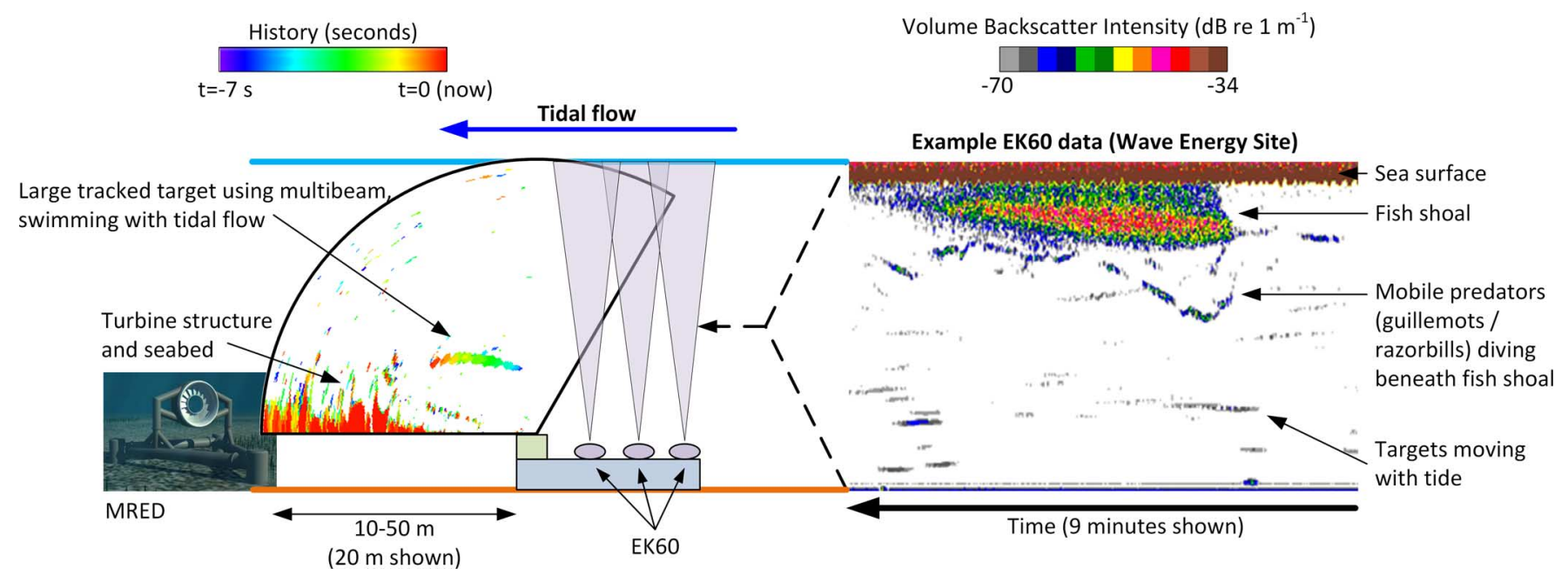

Fig. 3. Setup of the FLOWBEC acoustic imaging platform. The Imagenex MBES images the MRED together with the water column along the axis of tidal flow for target tracking and monitoring the interactions of targets with the MRED. The Simrad EK60 multifrequency echosounder faces vertically upwards for target identification, abundance estimates and measures of the morphology of turbulence. The left image shows a target tracked using the MBES at 8 frames per second for a duration of 7-s at the EMEC Tidal Energy Site, observed swimming with the tidal flow and tracked over $10 \mathrm{~m}$ in the vicinity of a turbine structure. The right image is a 9-min excerpt from the EK60 echosounder at the EMEC Wave Energy Site, showing a large fish shoal near the sea surface and mobile predators confirmed by concurrent shore-based bird observations to be guillemots/razorbills diving beneath and feeding on the fish shoal.

and data storage, in separate pressure vessels for reliability, as well as flexibility of development and deployment [29].

The Delta T MBES operates at $260 \mathrm{kHz}$, imaging a wide swath of $120^{\circ}$ by $20^{\circ}$, with 120,240 , or 480 beams, 500 range bins and at repetition rates of up to 20 pings/s. Its range can be adjusted from 0.5 to $100 \mathrm{~m}$ and all parameters (range, gain and ping scheduling) can be controlled programmatically via TCP commands in real-time during operation. The wide swath was selected to provide a wide acoustic volume to increase detection rates. The Delta T MBES was preferred for its low cost and low power consumption (typically $<10 \mathrm{~W}$ ), with similar Imagenex Delta $\mathrm{T}$ models having already been used successfully for a variety of applications [30], [31]. The MBES measures the backscattering strengths (in $\mathrm{dB}$ ) of all targets, relative to a root mean square (rms) source level of $190 \mathrm{~dB}$ re $1 \mu \mathrm{Pa}$.m (Patterson, pers. comm., 2012). Pulse lengths vary with the range setting (e.g., $300 \mu \mathrm{s}$ at $50 \mathrm{~m}$ range). The multibeam was not calibrated for this study; consequently, all backscatter measurements are considered relative not absolute. Relative comparisons between measurements/deployments are valid if the same gain setting is used during acquisition and saturation does not occur.

The three frequencies of the EK60 echosounder $(38,120$, and $200 \mathrm{kHz}$ ) have $7^{\circ}$ conical beams. Comparison of scattering strengths at the different frequencies enables identification of fish species, and this echosounder has also been used successfully to examine diving seabirds (e.g., [32]).

1) Orientation: Fig. 3 illustrates with real data the orientation of the two sonar systems and what is gained from their synergy. The three Simrad EK60 transducers are orientated vertically upwards, facing the water surface to image targets in the tidal flow. The MBES overlaps the EK60 beams in space and is aligned with its $120^{\circ}$ swath orientated parallel to the tidal flow, and inclined so that the outer beams are parallel to the seabed to include the MRED within the swath. Using this orientation,

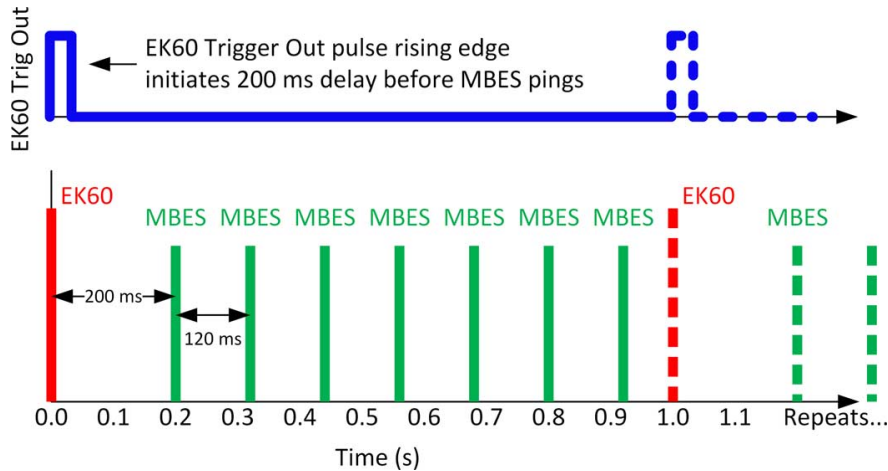

Fig. 4. Operation of the EK60 and MBES is synchronized using a trigger pulse and adjustable ping sequences to avoid acoustic interference between the two systems.

diving seabirds can be detected above water by the shore-based radar and bird observer, before being tracked underwater in the tidal flow, and the interactions of fish, seabirds and marine mammals with the MRED can be monitored.

The number of returns from a target is dependent on the target speed, swath geometry, pulse repetition rate $(7-8 \mathrm{~Hz})$ and the degree of alignment of the target trajectory with the multibeam swath. Targets swimming across-swath, in the $20^{\circ}$ rather than $120^{\circ}$ along-swath direction will be present in the swath for fewer pings and thus detected, but potentially not tracked. However, given the often near-symmetric and largely bidirectional flow of sites selected for tidal stream turbine installations, and the general preference of fauna to dive or swim with/against the flow, alignment of the multibeam swath with the major axis of the tidal flow maximizes the distance/time a target will be detectable within the $20^{\circ}$ across-swath beamwidth.

2) Synchronization and Timing: Although not transmitting at the same time, the two sonar systems image overlapping volumes of the water column, sometimes up to and including 
the sea surface. A ping synchronization interface was developed to avoid acoustic interference between the two systems and a clock synchronization interface ensured that the logging remained synchronized over a 14-day deployment. The ping rate of both systems is customizable, allowing for a variety of sampling methods. The standard ping sequence of interspersed EK60 and MBES pings is shown in Fig. 4, where all three EK60 transducers transmit simultaneously, followed by a $200-\mathrm{ms}$ decay period, then seven MBES pings at 120-ms spacing before the next EK60 ping. Testing in a tank (at the University of Bath and Marine Scotland Science, Aberdeen, U.K.) and in the field (at Vobster Quarry, Somerset) with a range of depths and ping spacings, and hydrophone measurements ensured that acoustic interference between instruments and between adjacent pings was minimized.

Acoustic synchronization is achieved using a master (EK60)/ slave (MBES) arrangement. The EK60 system is configured with the desired repetition rate (e.g., 1-s) and generates a TTL synchronizing pulse with each ping. The rising edge of this synchronizing pulse is detected by the MBES controller using a National Instruments USB-6008 data acquisition board, which schedules a customizable delay before the required MBES ping sequence. MBES pings are triggered by direct TCP ping scheduling of the Delta T multibeam using software originally written for synchronization of a similar Imagenex multibeam with other sonar devices on an ROV [30].

A timeout is used for triggering the multibeam pings to ensure resilience in the case of failure of the EK60 trigger pulse. If an EK60 trigger pulse is not received by the MBES for a set period, for example 2-s, then the MBES triggers a ping sequence anyway. This ensures a MBES dataset will be gathered even in the case of EK60 failure. Acoustic interference is a risk if the EK60 is still transmitting and the failure is in the trigger line; however this will only corrupt a small portion of the data. Synchronization is reestablished if/when the trigger pulses resume.

Both the EK60 and MBES systems use a low-power small form-factor (approximate dimensions $11.5 \times 10.1 \times 2.7 \mathrm{~cm}$ ) x 86 computer running Microsoft Windows XP for sonar data acquisition and storage onto a solid-state disk. The EK60 uses standard Simrad software to control the EK60 and record data. The MBES uses a bespoke compiled version of the Imagenex Delta $\mathrm{T}$ control software, and custom code written in National Instruments LabVIEW to read the synchronizing pulse and to schedule MBES pings. System health data (battery voltage, timing data, etc.) is also logged using LabVIEW interfaced to the USB-6008 board.

\section{Tilt Heading Depth (THD) Sensor}

An Oceantools Tilt Heading Depth (THD) sensor is mounted on the frame and logs frame pitch, roll, yaw (magnetic heading), and depth (pressure) at $4 \mathrm{~Hz}$ throughout the survey. Pitch, roll and yaw are used to verify that the frame remains stable throughout a survey and to confirm orientation of the multibeam swath. Deployment sites are carefully selected with prior knowledge of detailed bathymetry and seabed roughness-typical static deviations in pitch and roll are $<2^{\circ}$, with typically $<1^{\circ}$ of movement of the frame in pitch and roll even in the

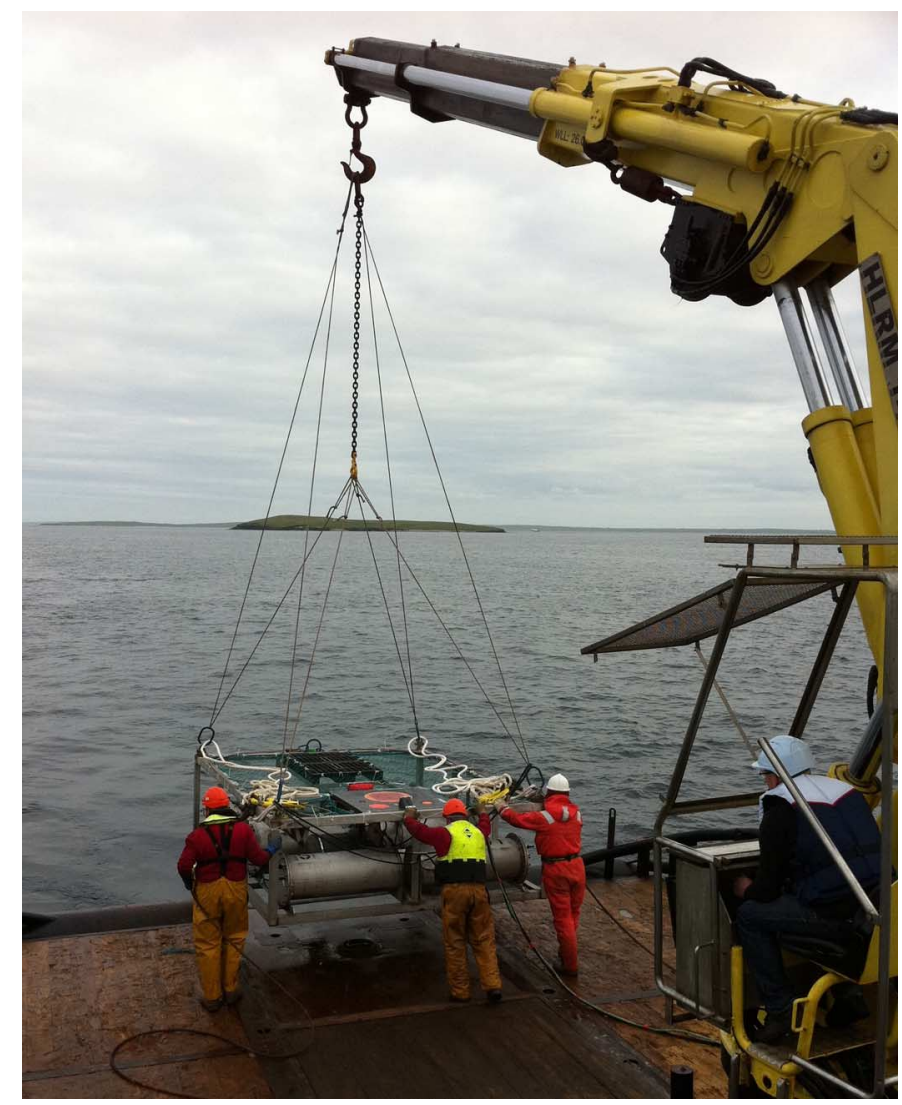

Fig. 5. Deploying the FLOWBEC frame. A complex arrangement of bridles is used to lower the frame to the seabed, before a surface-actuated hydraulic release leaves the frame on the seabed in 20 min with no trailing lines-essential for surveys in tidal sites.

highest tidal flows. Depth (pressure) is used to measure tide height and can also be used as an approximation of wave height.

\section{E. $A D V$}

A SonTek/YSI ADVOcean Acoustic Doppler Velocimeter (ADV) was added to the frame for the 2013 deployments, to measure 3-D water velocity throughout a deployment. Data are acquired at $20 \mathrm{~Hz}$, allowing for measurements of mean water velocity, waves and turbulence. The unit includes additional sensors which also sample at $20 \mathrm{~Hz}$, including a pressure sensor for surface-level measurements, a temperature sensor for automatic sound speed compensation and background ecological data, and a 3-axis tilt sensor to confirm stability of the frame at this high rate. Signal strength is also recorded, and it can be used as a qualitative measure of sediment fluctuations and a quantitative measure of sediment concentration if the type of sediment is known (e.g., using the techniques described in Thorne et al. [33]).

The ADV probe was mounted within the FLOWBEC frame steelwork to protect the sensitive probe from damage during deployment and recovery. Although the mounting location was selected to minimize turbulence caused by the flow of water through the frame, some frame-derived effects may still persist. Methods to mitigate this using 3-D hydrodynamic model data are discussed in later sections. 


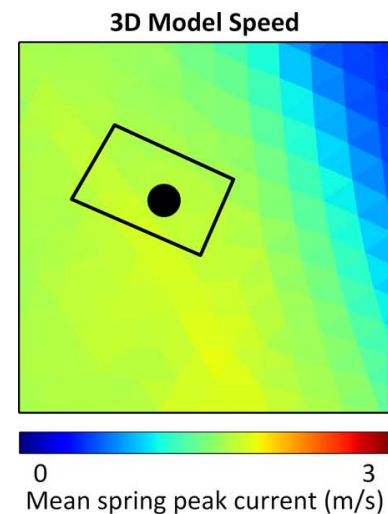

3D Model Vertical Turbulence

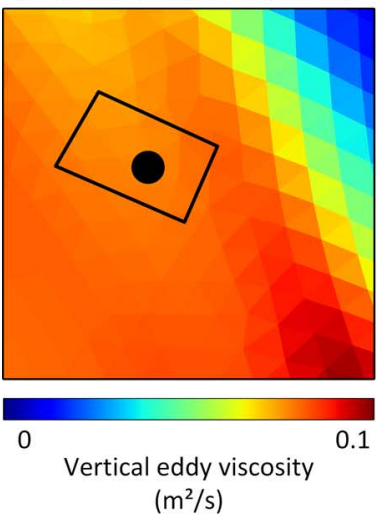

2013 FoW1 frame

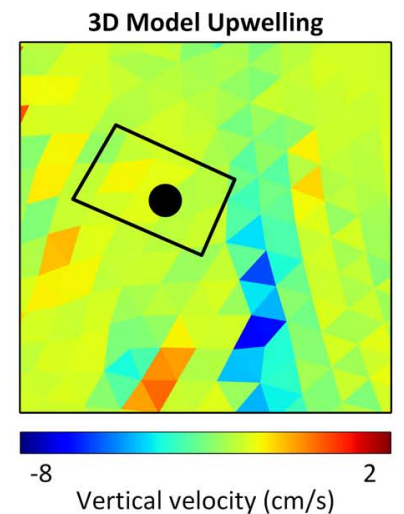

3D Model Horizontal Turbulence

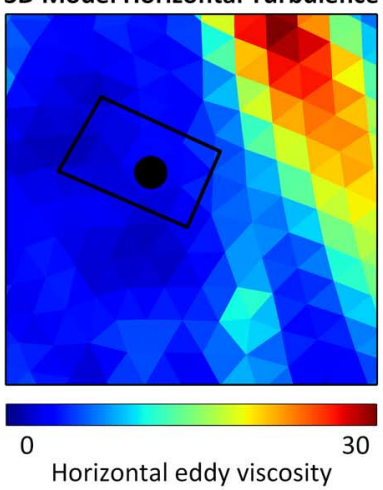

$\left(\mathrm{cm}^{2} / \mathrm{s}\right)$

Radar Sea Surface Roughness

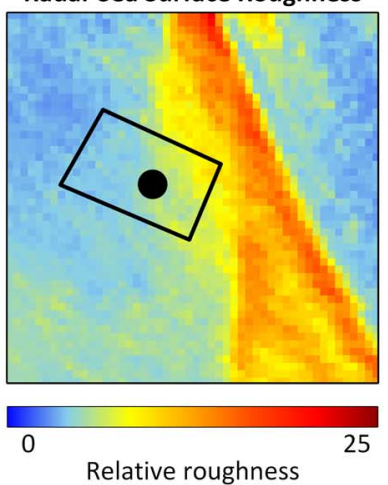

Bird observations / minute

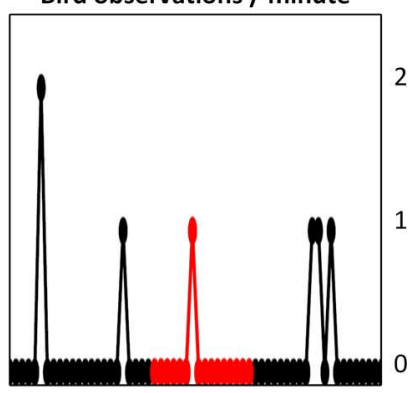

Time (1 hour total)

$\diamond 2013$ FoW1 bird observation area (370×235 meters)

Fig. 6. A variety of additional measurements and model datasets are available for each deployment site. All maps show an extent of $1 \times 1 \mathrm{~km}$, with the 2013 FoW1 (Fall of Warness \#1) frame position and bird observation area marked. The location of this $1 \times 1 \mathrm{~km}$ section in the context of the wider tidal energy site is later shown in Fig. 7. 3-D hydrodynamic model data were provided by P. Cazenave and R. Torres [35]. Model speed shows the mean of a 12-h period surrounding peak spring flow. Corresponding radar sea surface roughness is shown at 20-m resolution. The shore-based bird observations corresponding to this time are shown in red. An interesting correlation between modeled turbulence and measured roughness can already be seen.

\section{F. Fluorometer}

A WET Labs ECO FLNTUSB fluorometer was also added to the frame for the 2013 deployments in an upward facing orientation, to measure chlorophyll fluorescence (excitation wavelength of $470 \mathrm{~nm}$, emission wavelength of $695 \mathrm{~nm}$ ) at 10-min intervals, as a proxy for phytoplankton [34]. This is used to complement acoustic estimates of plankton using the EK60 echosounder. An optical measure of turbidity at a wavelength of $700 \mathrm{~nm}$ is used to provide turbidity measurements which are not affected by colored dissolved organic matter (CDOM) measurements.

\section{G. Deployment and Recovery Procedure}

Deployment and recovery is performed using a small boat (23 m length overall), minimizing cost. The deployment and recovery procedures are designed around the relatively short period of slack water at the tidal energy test sites, which can be as little as $20 \mathrm{~min}$ in Orkney (the currents never drop to completely still water). All logging is started on deck in advance of deployment and operation is verified using a Wi-Fi connection until the platform is submerged.

The frame is deployed with its heading aligned with the major axis of the tidal flow. The deployment boat uses a multipoint mooring to align itself with the major axis of tidal flow at slack water. A deck crane is used to maneuver the frame overboard (see Fig. 5), before the weight is transferred to a pair of deployment bridles connected to two winch wires running over the bow roller, one to each side of the frame. Each deployment bridle is permanently fixed to the winch wire, then passes through a master link at the fore and aft corners of the frame on that side, before returning to a hydraulic shackle on the winch wire.

The winch wires are paid out at an equal rate, monitored on deck, and the subsea position of the frame is monitored using a USBL transponder on each winch wire. This provides real-time feedback of frame position, depth and confirmation of the frame heading with the major axis of tidal flow, using the baseline distance between transponders. A SCANMAR inclination sensor is permanently mounted on the frame itself and provides throughwater acoustic confirmation to the surface, during deployment, that the frame is sited level and stable on the seabed before it is released. Under these challenging conditions of 20-min windows at slack water, horizontal siting accuracy is typically $<3 \mathrm{~m}$ in water depths of 30-50 $\mathrm{m}$ with a heading accuracy of typically $<10^{\circ}$. This accuracy permits reliable deployment in close proximity to MREDs, typically 10-20 $\mathrm{m}$ to allow the MRED and animal interactions to be imaged by the MBES.

Upon the correct frame position and heading being achieved, the hydraulic shackles are opened and the frame is deployed 


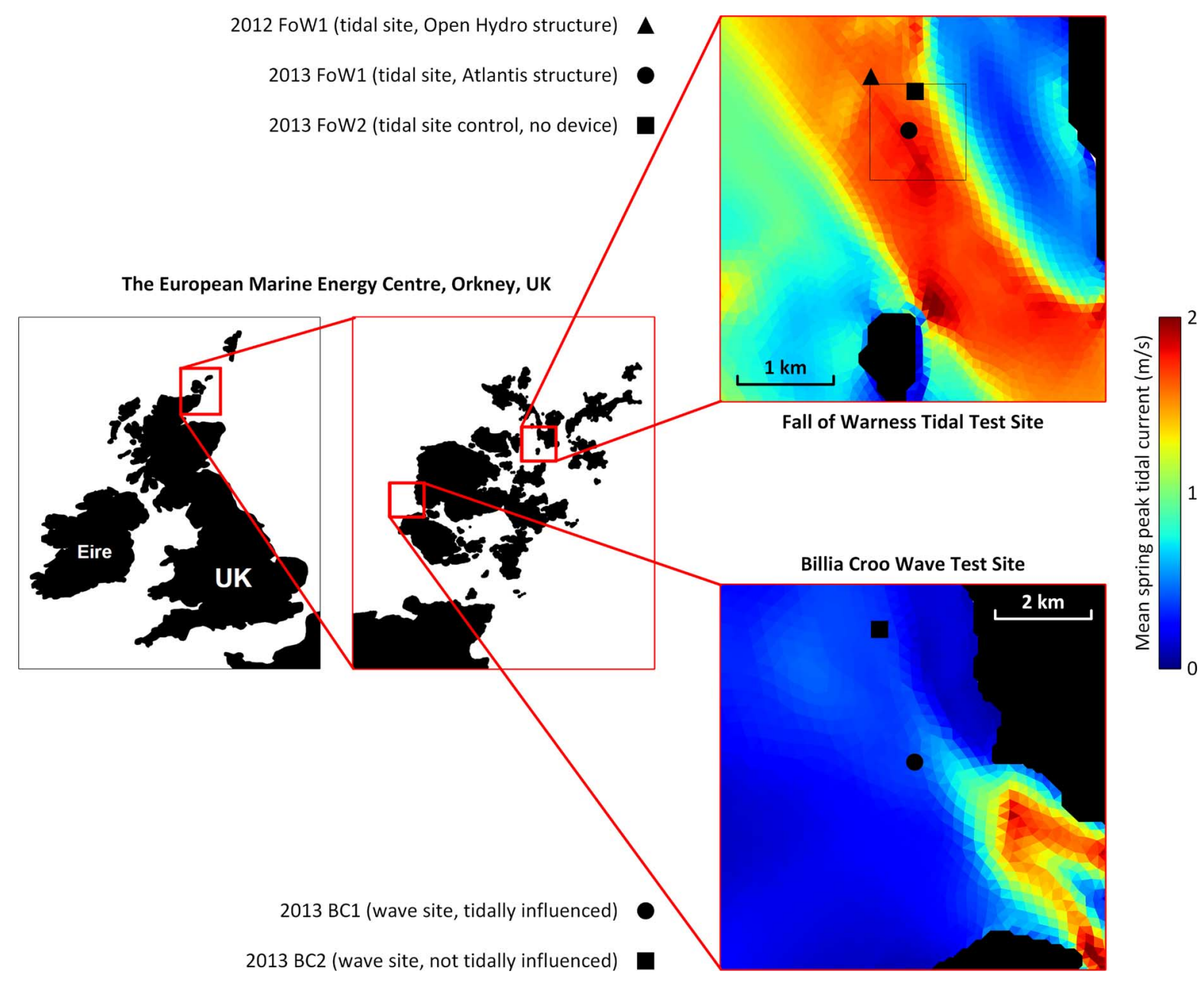

Fig. 7. Five 14-day deployments of the FLOWBEC frame were carried out in wave and tidal test sites, both adjacent to MRE structures and in control areas free from MREDs. The map shows mean spring peak tidal current, which is the mean of a 12-h period surrounding peak spring flow from model outputs provided by colleagues P. Cazenave and R. Torres [35]. The $1 \times 1 \mathrm{~km}$ square in the Fall of Warness site is the location of the example datasets shown previously in Fig. 6 .

on the seabed with no lines, anchors or marker buoys which could become entangled in the tidal flows or compromise the measurements.

In strong tidal areas, the frame is deployed without any marker buoy, and recovery is performed using an ROV to locate and connect a recovery line to the frame. The ROV lands on a purpose-designed rigid platform, where a large master link is mounted protruding upwards from the frame, to which the ROV attaches a Dyneema recovery line using a gated hook. The ROV then returns to the surface and tension is applied to the Dyneema recovery line. This tension breaks the loose tie-offs which hold the master link in place. This master link is connected to each corner of the frame via wire bridles, again secured via tie-offs for the duration of the survey. These tie-offs part upon recovery, allowing the frame to be lifted from each corner and maintained level.

For sites without strong tidal flows (e.g., the EMEC Wave Energy Site), the frame is deployed with a clump weight 200 $\mathrm{m}$ away, connected to the frame via a seabed line. This clump weight has a riser and marker buoy, but is far enough that it does not affect the frame measurements. Recovery is performed by hooking the marker buoy and lifting the clump weight, which in turn lifts the frame.

\section{H. Additional Measurements}

Data from the FLOWBEC subsea frame was complemented by a number of additional datasets. Detailed multibeam bathymetry for the tidal site was collected by the Maritime \& Coastguard Agency as part of the UK Civil Hydrography Programme at approximately $0.1-\mathrm{m}$ vertical and 2-m horizontal resolution, and provided by $\mathrm{R}$. Wynn through the MAREMAP project. A 20-depth layer, approximately $100-\mathrm{m}$ horizontal resolution (unstructured grid) 3-D hydrodynamic model was developed using Finite Volume Coastal Ocean Model (FVCOM) by project partners P. Cazenave and R. Torres at the Plymouth Marine Laboratory (PML), covering the entire Orkney region including the EMEC Wave and Tidal Energy Test Sites [35]. Model outputs were generated for all periods when the frame was deployed, at 15-minute intervals. Meteorological data for survey periods were made available by colleagues at EMEC (Dampney, pers. comm., 2013). A shore-based marine X-band radar was operated by coauthor P. Bell at the EMEC tidal site; it measures radar targets passing through the site at the water surface (birds, mammals, boats), surface derived currents and sea surface roughness [36]. Finally, shore-based wildlife observations focused on the frame deployment locations were 
TABLE I

Summary of FlOWBEC Datasets Acquired at MrED and Control Sites in 2012 and 2013, Underwater (Blue Shading) and Above Water (GREEN SHADING)

\begin{tabular}{|c|c|c|c|}
\hline Data type: & Location: & Approximate resolution: & Information available: \\
\hline EK60 & Underwater & $\begin{array}{l}0.2 \mathrm{~m} \text { range bins, } 1 \mathrm{~Hz} \\
\text { sampling }\end{array}$ & $\begin{array}{l}\text { Backscatter strength of all targets } \\
\text { (multifrequency identification, abundance, } \\
\text { morphology of turbulence, plankton) }\end{array}$ \\
\hline ADV & Underwater & Point measurement at $20 \mathrm{~Hz}$ & $\begin{array}{l}\text { XYZ water velocity, pressure, temperature, frame } \\
\text { heading, acoustic measure of turbidity }\end{array}$ \\
\hline THD & Underwater & Point measurement at $4 \mathrm{~Hz}$ & Frame pitch, roll, heading and pressure (depth) \\
\hline Bathymetry & Underwater & $0.1 \mathrm{~m}$ vertical, $2 \mathrm{~m}$ horizontal & Bathymetry, slope, roughness \\
\hline 3D model & Underwater & $\begin{array}{l}20 \text { depth layers (quadratic } \\
\text { distribution), approximately } \\
100 \text { m horizontal resolution } \\
\text { using an unstructured grid, } \\
\text { 15-minute intervals }\end{array}$ & $\begin{array}{l}\text { XYZ water velocity, measures of turbulence (bed } \\
\text { stress, turbulent kinetic energy, turbulent } \\
\text { horizontal and vertical diffusivity) }\end{array}$ \\
\hline Bird observations & Above water & $\begin{array}{l}\text { 1-minute intervals for up to } \\
\text { 6-hours per day }\end{array}$ & $\begin{array}{l}\text { Number and surface/diving behavior of seabirds } \\
\text { and mammals at each deployment location to } \\
\text { train detection algorithms and to ground truth } \\
\text { acoustic observations to species }\end{array}$ \\
\hline
\end{tabular}

conducted by coauthor J. Waggitt for up to $6 \mathrm{~h}$ per day, weather permitting, at both the wave and tidal sites. These observations were used to identify spatial and temporal trends in seabird distribution, to identify periods of high-intensity seabird activity above the frame, and to ground truth algorithms for autonomous detection and identification of sonar targets underwater with above-water observations of identified targets.

In summary, synchronized data were gathered underwater and above water at a resolution of several measurements per second across a range of physical and multitrophic levels, from phytoplankton, to zooplankton, to fish, seabirds and marine mammals - and complemented by model, radar, meteorological and bird observation data as detailed in Table I. Fig. 6 shows an example of the synergy between these datasets.

\section{Summary OF DePloyments}

To date, a total of five 2-week deployments have been achieved around the EMEC sites in Orkney as indicated in
Table II and Fig. 7. Deployments were conducted during the seabird breeding season which peaks in summer months [37]. Deployments close to MRE structures (10-20 m), and at "control" sites in areas free from MREDs, were carried out to assess the effect of the presence/absence of these structures.

In 2012, the first deployment at the Fall of Warness (FoW) tidal site (with $4 \mathrm{~m} / \mathrm{s}$ spring tides), $20 \mathrm{~m}$ from the OpenHydro Test Turbine provided an initial dataset (2012 FoW1) adjacent to a seabed structure representative of a MRED and verification of operation in the tidal site. This dataset was complemented by a 2013 deployment at a distance of $22 \mathrm{~m}$ from the Atlantis tripod base and piling (2013 FoW1). A third tidal site deployment in similar conditions but in an area free from devices provided a control (2013 FoW2).

A 2-week deployment at the Billia Croo (BC) wave site (typically $3-5 \mathrm{~m}$ wave height) in a tidally influenced area with up to $3.5 \mathrm{~m} / \mathrm{s}$ spring tides (2013 BC1) was performed for comparison to a similar non-tidally influenced area of the wave site with up to $1.5 \mathrm{~m} / \mathrm{s}$ spring tides (2013 $\mathbf{B C 2}$ ). 
TABLE II

Summary of Flowbec Frame Deployments, Frame Positions, Distance to MRED (If Any), and Duration

\begin{tabular}{|l|l|l|l|l|}
\hline \multicolumn{3}{|c|}{ Tidal Energy Site } & \multicolumn{2}{c|}{ Wave Energy Site } \\
\hline 2012 FoW1 & 2013 FoW1 & 2013 FoW2 & 2013 BC1 & 2013 BC2 \\
\hline $\begin{array}{l}59^{\circ} 9.29^{\prime} \mathrm{N} \\
2^{\circ} 50.03^{\prime} \mathrm{W}\end{array} 5^{\circ} 8.99^{\prime} \mathrm{N}$ & $59^{\circ} 9.22^{\prime} \mathrm{N}$ & $58^{\circ} 57.85^{\prime} \mathrm{N}$ & $58^{\circ} 59.38^{\prime} \mathrm{N}$ \\
\hline 20 m from Open Hydro & 22 m from Atlantis & $2^{\circ} 49.61^{\prime} \mathrm{W}$ & $3^{\circ} 23.00^{\prime} \mathrm{W}$ & $3^{\circ} 23.76^{\prime} \mathrm{W}$ \\
\hline 12 Jun - 27 Jun 2012 & 2 Jun - 15 Jun 2013 & 18 Jun - 5 Jul 2013 & 10 Jul - 24 Jul 2013 & 27 Jul - 12 Aug 2013 \\
\hline
\end{tabular}

\section{ACOUSTIC MONITORInG}

Processing of the acoustic data has so far focused on the MBES, with the EK60 used primarily for corroboration, confirmation of target identification, multifrequency identification of fish species as well as a measure of turbulence. The steps in processing the acoustic data comprise quality checks (QC), noiseremoval, acoustic intensity analysis, target detection, tracking and classification. These steps are considered briefly in the following sections, using the 2013 FoW1 dataset as an example.

The 2013 FoW1 FLOWBEC frame deployment was positioned in the EMEC Fall of Warness (FoW) site, approximately $22 \mathrm{~m}$ from the Atlantis AK-1000 $10 \mathrm{~m}$ high piling and approximately $15 \mathrm{~m}$ from a 4-m high block of the AK-1000 tripod base. The FLOWBEC frame was deployed up/down stream of the Atlantis turbine base, in alignment with the major axis of the tidal flow at this position, verified by onboard ADV measurements.

Data were stored as $117 \times 500$-MByte "837" files. The MBES data were converted from the proprietary " 837 " Imagenex Format to "83B" beam data using a custom build of the Imagenex Delta $T$ Software which disabled ping averaging (v1.04.54, narrow mixed beamwidth, gain equalization on). A custom LabVIEW program was written to index, display and analyses the files.

\section{A. Quality-Checks (QC)}

The acoustic noise affecting the MBES comes mostly from interference from the EK60 and reflections from the sea surface, including potentially out of range returns from previous pings. All are relatively straightforward to mitigate due to their regular patterns of manifestation.

1) EK60 Interference: There is a risk of interference from the EK60 whenever synchronization between the EK60 and MBES is lost. Occasional missed pings are inherent to operation of the EK60 system using the standard configuration, and occur in vessel-mounted installations as well as with the FLOWBEC frame (Hunter, pers. comm., 2013). These occur approximately 200 times per 14-day survey and result in a trigger pulse not being sent to the MBES, and therefore the MBES resorting to a 2-s timeout before scheduling a standard ping sequence every $2 \mathrm{~s}$, until synchronization resumes a few seconds later. During this period of unsynchronized MBES pings, if one or more of the EK60 transducers transmits (e.g., one of the frequencies other than the $120 \mathrm{kHz}$, which generates the trigger pulse), then there is a risk of interference. This manifests itself on the MBES as a radial band of noise with high intensity on the center beams, as shown in Fig. 8.
All timing details (e.g., EK60 trigger pulse rising and falling edge, MBES transmit and receive events) are logged, and the MBES timeout periods are therefore easily viewed to inspect for EK60 noise. Robust autonomous algorithms can reliably detect this noise. The sum of all beams is plotted against range (blue line in the rightmost plot of Fig. 8), and smoothed by a zero-phase moving-average filter. A peak detection algorithm then identifies the EK60 noise using a peak width and amplitude threshold, due to the high intensity and radial nature of the noise.

While the region surrounding the radial band of noise can be masked and the rest of the frame kept, due to the very few occurrences of these corrupted frames, they are simply removed from analysis. Of the typically 200 instances when synchronization is momentarily lost throughout a 14-day survey, typically only 12 frames are corrupted by EK60 noise (out of 8.4 million pings $=0.00014 \%$ ).

The EK60 control system has since been modified to generate a synchronizing trigger pulse from transmission of any of the frequencies, mitigating this source of interference for future deployments.

2) MBES Reflections: In addition to interference from the EK60, the MBES data can be affected by intrinsic noise and spurious reflections.

The first principal artifact manifests as cross-beam spreading, where a strong return at a particular range on one or more beams causes artifacts across other beams at this range. This is apparent in Fig. 8, where the region of the water column at ranges greater than the sea surface height is corrupted by noise (seen in the leftmost part of the swath, in the water column past the turbine). The range of this radial noise varies as the sea surface moves up and down with the tides, helping in its early identification. At a later stage, it may be possible to mask this noise, or to apply a threshold if the signal-to-noise (SNR) ratio is sufficiently high that true targets are of greater intensity than the noise. Analyses presented here restrict target tracking to a radial Region Of Interest (ROI) delineated by an upper limit range set to the minimum sea surface height (spring low tide). This cross-beam spreading occurs with any high-intensity target, including the turbine and seabed. In this case, the position is static and so the radial band of noise is persistent in space, although of lower intensity and not visible in Fig. 8. This is later removed using a simple intensity threshold.

The second type of artifact manifests as reflections about the center beam of the MBES. The reflection of the sea surface can be seen in Fig. 8; its position changes with tide height. Reflec- 

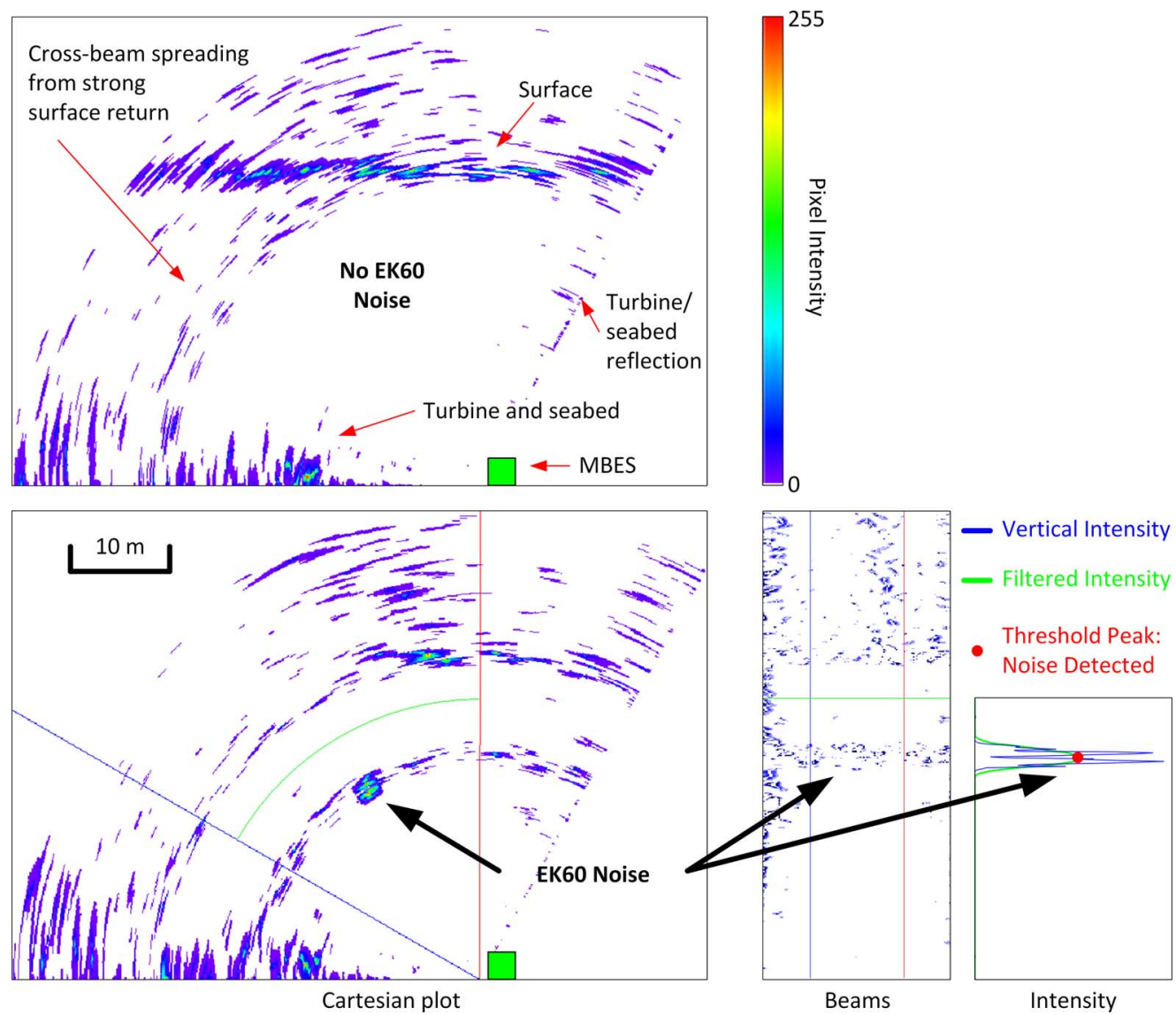

Fig. 8. Two raw pings from the Delta T MBES. The upper figure shows a typical scan, the lower figure shows a ping corrupted by EK60 noise. The noise characteristics are shown in the Cartesian and beam plots. The noise is detected using a peak detection algorithm operating on the filtered sum of range bins for the water column region of interest (right-most plot)

tions from the turbine and seabed can also be seen in the rightmost beams above the frame, fixed in space. The shallow depths at which the MBES and EK60 are deployed, coupled with the angles of their beams relative to the sea surface (of roughness varying with sea state, sometimes presenting different facet orientations) induce the possibility of multiple reflections or outof-range returns from previous pings. Depending on the actual ranges, these might not be attenuated too much, and might still be visible, especially for rougher sea states. At wave sites, reflections from the different elements of the MRED might also occur next to the sea surface, within the acoustic field of view, as it moves along the main wave direction.

As with all noise, there are two options to mitigate the effects-either to attempt correction such that it no longer has an effect on the results, or to mask the region to exclude it from analysis.

Noise correction preserves data, at the risk of either false negatives (removing valid targets) or false positives (noise being falsely detected as targets). Techniques include intensity thresholding which requires that all targets always have greater intensity than the noise, or using information from preceding/successive frames (such as $\mathrm{min} / \mathrm{max} /$ mean techniques) which require that the noise has a known pattern, at the risk of removing targets coincident with the noise.

Removing affected areas from the analysis is safest in terms of false positives and false negatives when separating targets from artifacts, but requires discarding data. This cautious approach is used for the initial analysis of the MBES data. Later stages will keep the affected data once reliable noise-rejection algorithms have been developed and typical target SNRs in the study areas are better understood.

The red, green and blue lines in Fig. 8 show an initial ROI delineating the water column in both Cartesian and beam plots. As the water depth and MRED presence varies with each deployment, these are adjustable (and can be later varied over time to allow for varying tide height). The blue line delineates the seabed and turbine, the red line delineates seabed/turbine reflections around the nadir, and the green line delineates the sea surface at spring low tide.

3) Turbulence: Turbulence is included in quality control as its effects can mask valid targets or create false ones. If turbulence can be correctly identified and delineated, then measures of its morphology can serve as a useful tool to characterize habitats in these high-energy sites. The turbulence is most noticeable on the EK60 echogram as large subsurface Kolk boils of entrained air which can reach down into the water column, almost to the seabed in some areas of the tidal site. The occurrence of these boils depends on tide speed and direction, but also on position within the site, being strongly affected by the tidal flow around raised bathymetry and the neighboring islands. Fig. 9 shows an example of this turbulence on the EK60 echosounder. 

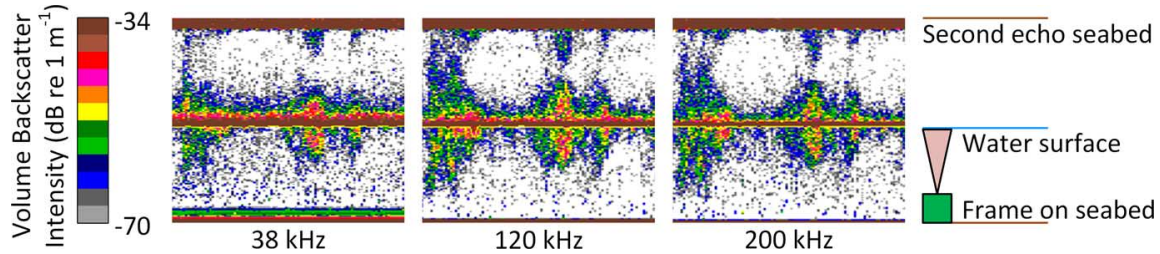

Fig. 9. Turbulence is clearly visible on all three frequencies of the EK60 echosounder, apparent during periods of high tidal flow as large subsurface Kolk boils which can reach down in the water column, almost to the seabed. The $\mathrm{x}$-axis shows a common timescale totaling approximately 3-min, sampling every second. The y-axis shows the acoustic backscatter intensity throughout the water column. The standard Time Varied Gain (TVG) [38] has been applied in Echoview.

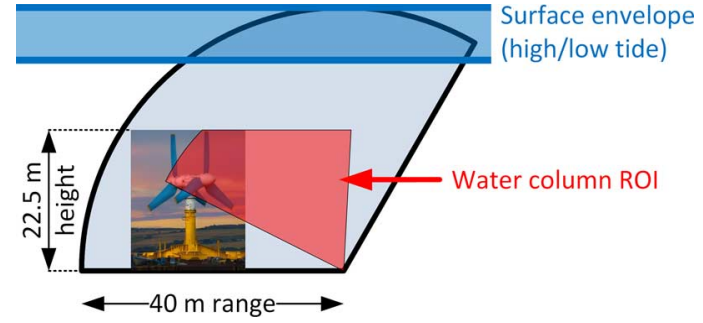

Fig. 10. 2013 FoW1 deployment used a multibeam range of $40 \mathrm{~m}$ to fully encompass the Atlantis AK-1000 tripod base and piling (nacelle and blades not present, the swath included the expected blade radius). The FLOWBEC frame was deployed approximately $15 \mathrm{~m}$ from a $4 \mathrm{~m}$ high leg of the tripod base, and approximately $22 \mathrm{~m}$ from the $10 \mathrm{~m}$ high center piling. The $66^{\circ} 30.4-\mathrm{m}$ range sector (shown in red) was cropped to a height of $22.5 \mathrm{~m}$ above the seabed to delineate targets at a vertical height overlapping the turbine structure and expected blade radius.

\section{B. Acoustic Backscatter Intensity Analysis}

Initial analyses of the multibeam data looked at the intensity of acoustic backscatter in each region of the swath over time, state of tide and space - where space is both horizontal and vertical distribution in the water column, and distribution between different survey sites (e.g., MRED presence/absence).

The swath was divided into three regions: 1) the water column ROI (defined previously), where variation in acoustic intensity over time should correspond to targets and possibly turbulence; 2) the turbine/seabed ROI where variation may also include the wake effects of turbulence with tide speed/direction and finally; 3 ) the sea surface, where variation may also be linked to sea surface roughness caused by wind and tide. These datasets were analyzed as a function of tide speed and direction (from the ADV, model data and radar derived currents), by daylight hour, by sea surface roughness (from the radar and meteorological data) and in conjunction with the shore-based bird observations.

\section{Target Analysis}

Acoustic intensity analysis can provide an overview of general trends, and the high MBES resolution allows specific targets to be detected and tracked as a function of time, tide and space. The development of this target tracking is beyond the scope of this paper and will form the basis of a later publication (Williamson et al. in prep.). The following figures provide a summary of the first analyses of targets tracked in the 2013 FoW1 deployment (adjacent to the Atlantis turbine structure) in a ROI defined to include the water column of height overlapping the turbine structure and expected blade radius (see Fig. 10).

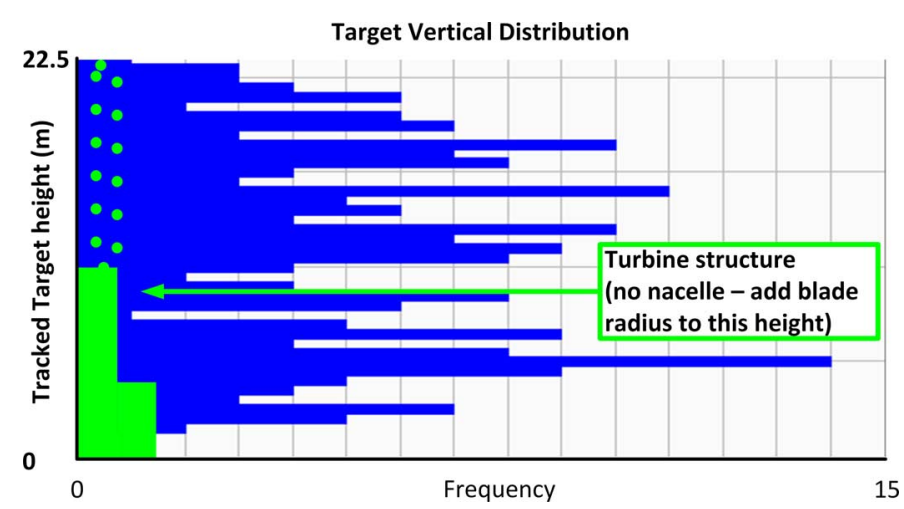

Fig. 11. Vertical distribution of tracked targets over the 12-day survey shows that there are a significant number of targets at a height where they are likely to encounter the turbine structure (or blades when present).

An intensity threshold of 140 (defined on the scale of 0-255 measuring backscatter using relative arbitrary units) was applied to the WC ROI defined in Fig. 10. This resulted in a total 186 tracks of three frames or more for the 2013 FoW1 deployment within the vertical height overlapping the Atlantis turbine structure. Fig. 11 shows the vertical distribution of these tracked targets. The Atlantis turbine structure is shaded in green and the dashed outline indicates the expected radius of the blades (not present during this survey).

\section{Target Classification and Species Identification}

The next step is target classification, to guide species identification, and to allow analysis by time, tide and space for a specific category of targets.

Target classification is possible using a variety of methods. The target morphology (size, shape, intensity, number of targets per frame, target separation) and behavior (velocity, velocity relative to water column, directionality, vertical distribution and intertarget interaction) are all measured using the multibeam, and classification can be performed by defining ranges for the various parameters. Fig. 12 shows four examples from the 2013 FoW1 deployment, containing a large shoal of fish, an individual target, a smaller, more densely packed shoal of fish (possibly a different species) and a diving seabird.

The shore-based wildlife observations can be used for ground-truthing, particularly for identifying seabird species on the multibeam by their distinctive dive behavior. A subset of shore-based bird observations can be used to first validate their acoustic detection by both sonar instruments, and second to use the known identification of species to 'train' software to pick 

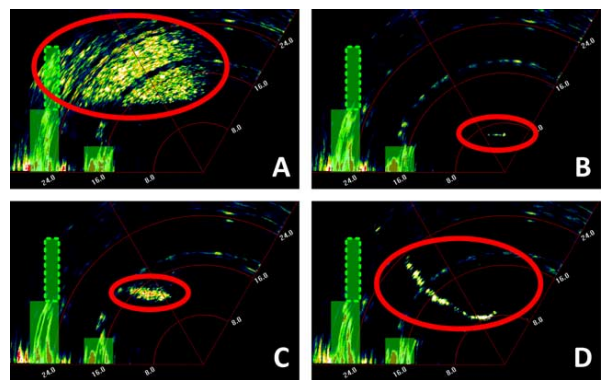

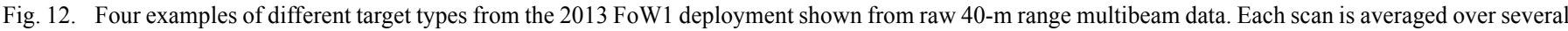

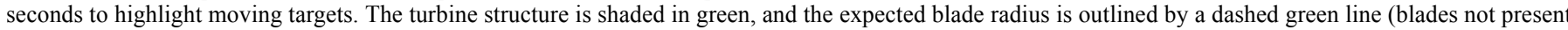

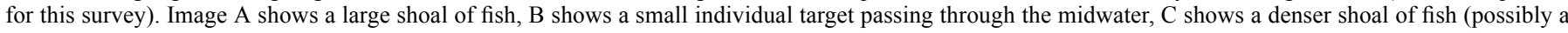
different species) and D shows a diving seabird. Ranges are shown in meters, also giving an indication of target sizes.

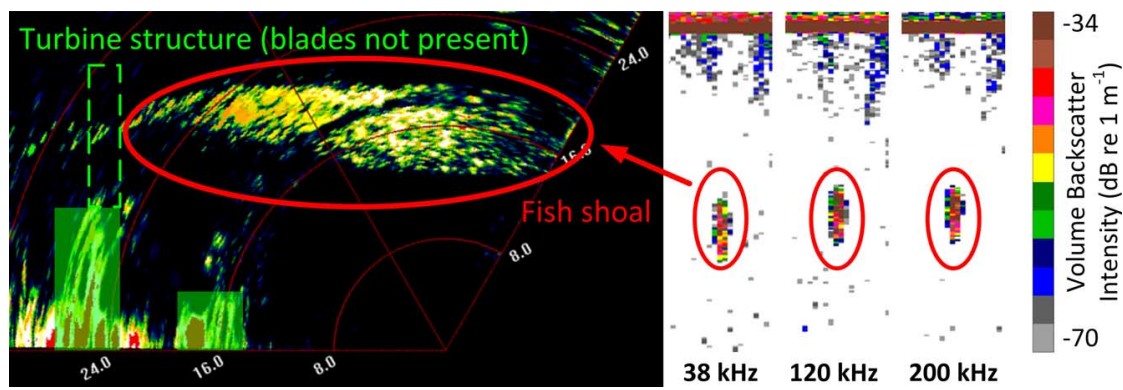

Fig. 13. Left: the multibeam swath shows a large fish shoal, tracked over 12-s. The turbine structure is outlined in green. The turbine blades (not fitted) are outlined in dashed-green. Right: the same target is detectable using the EK60 and the frequency response can be used to aid target identification [17].

out different species. The software can then be tested with the remaining shore-based observations.

Target classification is also possible using multifrequency analysis from the EK60 echosounder data. For fish, the known multifrequency 'signature', or frequency response, of different fish species can be used to identify pelagic and demersal species [17]. It can also be used to train software to pick out and track a range of different shoaling/feeding behaviors, using the EK60 for identification and the MBES for tracking. Fig. 13 shows an example shoal on both the MBES and EK60 echograms. The frequency response of diving seabirds [32], [39] can later be combined with shore-based observations to identify known birds and investigate prey-predator relationships. The further development of target tracking and classification algorithms will form the basis of a later publication (Williamson et al. in prep.).

\section{DISCUSSION}

\section{A. Using the FLOWBEC Platform for Environmental Monitoring Around MREDs}

Repeated deployments of the FLOWBEC frame in 2012 and 2013 amounted to 10 weeks in wave and tidal energy sites, both adjacent to MREDs and in control areas. They demonstrated the capabilities of the FLOWBEC platform in monitoring the environment around MREDs. The FLOWBEC frame permits a continuous 14-day survey from a stable platform without the cost, logistics, station-keeping and potential ecological influence of a surface platform or vessel [21], [40]. These deployments also showed that the fast, 24-hour servicing turnaround before the next deployment could be achieved repeatedly. Subsea measurements allow the interactions and water column use of predators and prey to be measured and compared to surface observations. The use of acoustics allows continuous surveys, 24-h a day, irrespective of visibility or illumination. Performing deployments both adjacent to MREDs, and in areas free from MREDs yet subject to similar environmental conditions (bathymetry, substrate, tidal flow), also provides an opportunity to compare the behavior and presence of animals between sites where the only significant change is the presence/absence of a MRED.

Acoustic transmissions might affect the presence and/or behavior of the species being studied, particularly marine mammals [26], [41]. This is important for low-frequency systems matching specific animal audiograms and transmitting at levels loud enough to affect them at these ranges. The FLOWBEC platform uses high frequencies $(38,120$ and $200 \mathrm{kHz}$ for the EK60, $260 \mathrm{kHz}$ for the MBES). The EK60 uses narrow beams, pointing upwards to the rough sea surface. The MBES uses a wide beam, pointing upwards at an angle and also eventually scattering on the same, rough sea surface. Preliminary calculations showed that most of the energy would be likely to decay to background levels within ranges of approximately $160 \mathrm{~m}$ and 80 $m$ respectively, i.e., within a few reflections. A recent study [41] detected low-frequency sidelobes in high-frequency sonars, including a different type of Imagenex multibeam, but this effect has never been documented for the Imagenex 837 multibeam, despite many years of use. Animals were seen actively foraging above the FLOWBEC platform during sonar operation.

Another limitation of active acoustics is limited range/coverage at these high frequencies, although it is orders of magnitude less significant than optical methods. It is here 
that multisensor integration is most useful, with wider scale and longer duration datasets. The FLOWBEC project already includes shore-based radar and complementary projects are investigating the effects of MREDs at wider scales [16]. There is also the opportunity to synchronize video footage from turbine-mounted cameras to confirm species identification and fine-scale behavior when visibility and illumination permit [24], to use as ground-truthing data for acoustic measurements at other times. A possible extension to the FLOWBEC platform is to duty-cycle Passive Acoustic Monitoring (PAM) with periods of active acoustics for longer-range passive detection of cetaceans, or to use PAM to intelligently trigger active acoustics when a vocalizing species of interest is in close proximity, to then measure small-scale behavior and interactions with the MRED using active acoustics.

\section{B. Environmental Impacts of MREDs}

The outcome of the tracking analysis will allow the environmental effect of MREDs to be explored using the distribution of targets (plankton, fish, birds, marine mammals) and predatorprey interactions with time, tide and space, where space includes vertical use of the water column, and horizontal distribution around the wave and tidal sites, and how all of this changes with the presence and absence of MREDs. The vertical habitat preferences of these ecological groups and collision risks can also be evaluated by looking at spatial overlap with MREDs, and collision risk predicted by looking at the overlap with conditions favored for MREDs.

Starting at the base of the food chain, the EK60 data can be used to relatively quantify the biomass of zooplankton in the water column and the fluorometer used for a relative measure of chlorophyll. This information can be used in wider analysis to test if changes in these lower tropic levels (which can be monitored easily and cheaply in the long run) can predict the occurrence and behavior of fish, seabirds and mammals (depth of diving, etc.).

Different fish species, as well as different shoaling and feeding behaviors, can be classified using the EK60 for identification and the MBES for tracking. For seabirds, once autonomous detection algorithms have been developed for different species, the range of depths and underwater behaviors that different species of diving seabirds are likely to use will be identified. We can then also quantify amount of time spent in the water column near moving components in locations with and without MREDs to assess collision risk. Predator-prey interactions (i.e., between seabirds or mammals and fish) can be determined, and predictions made of how often and in what tidal/wave conditions predator-prey interactions are observed, and how this is affected by the presence/absence of MREDs. Changes in behavior (i.e., change in depth use, prey-type hunted) in the presences of MREDs can be fed into population and individual-based energetic models to determine population level effects.

\section{CONCLUSION}

Increasing commitments to renewable energy in short timescales have seen rapid development of marine renewable energy sources and devices. Little is known of the general effects of installing and operating MREDs, at all depths and in all environments. The FLOWBEC project addresses the challenge of monitoring a significant portion of animal activity, biological and physical dynamics within the water column and at the sea surface near MREDs, using below-the-water instruments like sonars and above-the-water sensors like radar.

Our unique technology and analytical approach are currently the only subsurface system to continuously capture fine-scale (several measurements a second, submetric resolution) data over a wide range of both physical and multitrophic levels (phytoplankton, zooplankton, fish, seabirds and mammals) and over time periods which encompass day and night differences as well as full spring/neap tidal cycles.

The Imagenex 837B Delta $\mathrm{T}$ provides high resolution range and backscatter information on a variety of targets around MREDs and in the water column. The combined use of a Simrad EK60 multifrequency echosounder enables identification of fish species and has the potential to also allow the identification of different seabirds and marine mammals. Fish, marine mammals and diving seabirds can all be followed in the course of their interaction with MREDs, above water and below water. Acoustic measurements are being analyzed as a function of time, tide, waves, modeled data, surface observations of wildlife and shore-based marine X-band radar to understand the hydrodynamic habitat preference of various functional ecological groups (benthos, plankton, fish, birds and marine mammals) and how individual species may use preferred flow conditions.

Through the modularity and flexibility of the frame design, additional instruments can be easily integrated and synchronized to provide complementary datasets, such as cameras and ADCPs. The flexibility of deployment and portability of the frame also facilitates its use at other sites. The results increase our environmental understanding of the effects of installing and operating MREDs and can be used to guide marine spatial planning, device design, licensing and operation, as these individual MREDs are scaled up to arrays and new sites are considered.

Techniques for analyzing the raw data and statistical modeling are being refined, such that the combination of the technology and the analysis will ultimately provide an affordable way to measure interactions of marine wildlife in high-energy locations and around foundations and active devices.

This combination of our current technology and analytical approach can help to derisk the licensing process by providing a higher level of certainty about the behavior of a range of mobile marine species in high-energy environments. This approach can firstly quantify collision risk for fish, seabirds and a range of mammals and secondly, by identifying any changes in behavior due to the addition of MREDs, this approach can be combined with a wider modeling approach that can use the individual differences in behavior to quantify possible population level effects.

It is likely that this approach will lead to greater mechanistic understanding of how and why mobile predators use these highenergy areas for foraging. If a fuller understanding and quantification of the biophysical conditions which mobile predators are using to capture prey can be achieved at single demonstrator 
scales and these are found to be similar at least at initial smaller array scales, the outcomes might lead to a wider strategic approach to monitoring and possibly lead to a reduction in the level of monitoring required at each commercial site.

\section{ACKNOWLEDGMENT}

The authors would like to acknowledge the technical support of D. Mackay (Hydro Products Ltd., U.K.) and J. Patterson (Imagenex Technology Corp., Canada) with the multibeam sonar, N. Collie, P. Copland, J. Hunter, B. Ritchie, C. Stewart, I. Davies, and colleagues at Marine Scotland Science, U.K., for integration on the FLOWBEC platform, P. Frith and P. Reddish (University of Bath, U.K.), S. Fraser (University of Aberdeen) and colleagues at the European Marine Energy Centre (EMEC). They would also like to acknowledge J. Campbell (Eday Ranger) and the Cockram family for supporting shore-based bird observations. 3-D hydrodynamic model data were kindly provided by colleagues P. Cazenave and R. Torres at Plymouth Marine Laboratory, U.K. Parts of this article were presented at the Underwater Acoustics Conference (Rhodes, Greece) in June 2014. The guidance from R. Chapman and the Editorial Staff, together with the constructive comments from the two anonymous reviewers, are gratefully acknowledged.

\section{REFERENCES}

[1] A. Azzellino, D. Conley, D. Vicinanza, and J. P. Kofoed, "Marine renewable energies: Perspectives and implications for marine ecosystems," Sci. World J., 2013

[2] A. Khaligh and O. C. Onar, Energy Harvesting: Solar, Wind, and Ocean Energy Conversion Systems. Boca Raton, FL, USA: CRC Press Inc., 2009.

[3] M. Mueller and R. Wallace, "Enabling science and technology for marine renewable energy," Energy Policy, vol. 36, pp. 4376-4382, 2008.

[4] M. A. Shields et al., "Marine renewable energy: The ecological implications of altering the hydrodynamics of the marine environment," Ocean Coastal Manag., vol. 54, pp. 2-9, 2011.

[5] M. J. Dadswell and R. A. Rulifson, "Macrotidal estuaries: A region of collision between migratory marine animals and tidal power development," Biol. J. Linnean Soc., vol. 51, pp. 93-113, 1994.

[6] A. B. Gill, "Offshore renewable energy: Ecological implications of generating electricity in the coastal zone," J. Appl. Ecol., vol. 42, pp. $605-615,2005$.

[7] J. W. Grecian et al., "Potential impacts of wave-powered marine renewable energy installations on marine birds," Ibis, vol. 152, pp. 683-697, 2010.

[8] O. Langhamer, K. Haikonen, and J. Sundberg, "Wave power-Sustainable energy or environmentally costly? A review with special emphasis on linear wave energy converters," Renewable Sustainable Energy Rev., vol. 14, pp. 1329-1335, 2010.

[9] C. Frid et al., "The environmental interactions of tidal and wave energy generation devices," Environ. Impact Assess. Rev., vol. 32, pp. 133-139, 2012

[10] A. E. Copping and M. J. O'Toole, OES-IA Annex IV: Environmental Effects of Marine and Hydrokinetic Devices U.S. Dept. Energy, 2010, PNNL-20034.

[11] G. Savidge et al., "Strangford Lough and the SeaGen Tidal Turbine," in Marine Renewable Energy Technology and Environmental Interactions, M. A. Shields and A. I. L. Payne, Eds. Berlin, Germany: Springer-Verlag, 2014, pp. 153-172.

[12] M. J. Witt et al., "Assessing wave energy effects on biodiversity: The Wave Hub experience," Philosoph. Trans. Roy. Soc. A: Math., Phys., Eng. Sci., vol. 370, pp. 502-529, 2012.

[13] M. A. Shields and A. I. L. Payne, Marine Renewable Energy Technology and Environmental Interactions. Berlin, Germany: SpringerVerlag, 2014
[14] D. W. Stephens and J. R. Krebs, Foraging Theory. Princeton, NJ, USA: Princeton Univ. Press, 1986.

[15] G. E. Hutchinson, An Introduction to Population Ecology. Hew Haven, CT, USA: Yale Univ. Press, 1978.

[16] J. J. Waggitt and B. E. Scott, "Using a spatial overlap approach to estimate the risk of collisions between deep diving seabirds and tida stream turbines: A review of potential methods and approaches," Marine Policy, vol. 44, pp. 90-97, 2014.

[17] R. J. Korneliussen, "The acoustic identification of Atlantic mackerel," ICES J. Marine Sci., vol. 67, pp. 1749-1758, 2010.

[18] A. S. Brierley and P. G. Fernandes, "Diving depths of northern gannets: Acoustic observations of sula bassana from an autonomous underwater vehicle," The Auk, vol. 118, pp. 529-534, 2001.

[19] H. A. Viehman and G. B. Zydlewski, "Fish interactions with a commercial-scale tidal energy device in the natural environment," Estuaries and Coasts, pp. 1-12, 2014.

[20] H. A. Viehman, G. B. Zydlewski, J. D. McCleave, and G. J. Staines, "Using hydroacoustics to understand fish presence and vertical distribution in a tidally dynamic region targeted for energy extraction," $E s$ tuaries Coasts, pp. 1-12, 2014.

[21] P. Schwemmer, B. Mendel, N. Sonntag, V. Dierschke, and S. Garthe, "Effects of ship traffic on seabirds in offshore waters: Implications for marine conservation and spatial planning," Ecol. Appl., vol. 21, pp. $1851-1860,2010$

[22] A. N. Popper, "Effects of anthropogenic sounds on fishes," Fisheries, vol. 28, pp. 24-31, 2003

[23] W. Richardson, C. Greene, Jr, C. Malme, and D. Thomson, Marine Mammals and Noise. New York, NY, USA: Academic Press, 1995.

[24] M. Broadhurst and S. Barr, "Short term temporal behavioural responses in pollack, Pollachius pollachius to marine tidal turbine devices; a combined video and ADCP Doppler approach," in Proc. 9th Eur. Wave Tidal Energy Conf., Southampton, U.K., 2011.

[25] A. S. Duerr and M. R. Dhanak, "An Assessment of the hydrokinetic energy resource of the Florida current," IEEE J. Ocean. Eng., vol. 37 no. 2, pp. 281-293, Apr. 2012.

[26] G. D. Hastie, Tracking Marine Mammals around Marine Renewable Energy Devices using Active Sonar Dept. Energy Climate Change, 2012, SMRU Ltd report URN:12D/328, unpublished.

[27] B. J. Williamson, P. Blondel, J. J. Waggitt, P. S. Bell, and B. E. Scott, "Field deployments of a self-contained subsea platform for acoustic monitoring of the environment around Marine Renewable Energy structures," presented at the 2nd Int. Conf. Underwater Acoust. (UA2014), Rhodes, Greece, 2014.

[28] B. J. Williamson et al., "Using the FLOWBEC seabed frame to record underwater interactions between diving seabirds, prey, hydrodynamics and tidal and wave energy structures," presented at the 2nd Environ. Impacts of Marine Renewables (EIMR 2014) Conf., Stornoway, Scotland, 2014.

[29] B. J. Williamson and P. Blondel, "Multibeam imaging of the environment around marine renewable energy devices," presented at the 11th Eur. Conf. Underwater Acoust., Edinburgh, UK, 2012.

[30] B. J. Williamson, M. Balchin, and W. M. Megill, "Towards mapping Nereocystis luetkeana kelp beds: Using the holonomic iROV SeaBiscuit and sonar fusion," presented at the 11th Eur. Conf. Underwater Acoust., Edinburgh, U.K., 2012.

[31] J. Woelfel et al., "Microphytobenthos of Arctic Kongsfjorden (Svalbard, Norway): Biomass and potential primary production along the shore line," Polar Biol., vol. 33, pp. 1239-1253, 2010.

[32] K. J. Benoit-Bird, K. Kuletz, S. Heppell, N. Jones, and B. Hoover, "Active acoustic examination of the diving behavior of murres foraging on patchy prey," Marine Ecol. Progress Series, vol. 443, pp. 217-235, 2011.

[33] P. D. Thorne, D. Hurther, and B. D. Moate, "Acoustic inversions for measuring boundary layer suspended sediment processes," J. Acoust. Soc. Amer., vol. 130, pp. 1188-1200, 2011.

[34] C. W. Proctor and C. S. Roesler, "New insights on obtaining phytoplankton concentration and composition from in situ multispectral Chlorophyll fluorescence," Limnol. Oceanography: Methods, vol. 8 , pp. 695-708, 2010.

[35] P. S. Bell et al., "Flow and benthic ecology 4D - FLOWBEC - An overview," presented at the 2nd Environ. Impacts Marine Renewables (EIMR 2014) Conf., Stornoway, Scotland, 2014.

[36] P. Bell, J. Lawrence, and J. Norris, "Determining currents from marine radar data in an extreme current environment at a tidal energy test site," presented at the IEEE Int. Geosci. Remote Sensing Symp. (IGARSS 2012), Munich, Germany, 2012. 
[37] N. P. Ashmole, "Seabird ecology and the marine environment," Avian Biol., vol. 1, pp. 223-286, 1971.

[38] E. J. Simmonds and D. N. MacLennan, Fisheries Acoustics: Theory and Practice. New York, NY, USA: Blackwell Science, 2005.

[39] J. Szczucka, "Acoustic studies of diving birds in the Arctic," in Proc. 3rd Int. Conf. Underwater Acoustic Measur.: Technol. Results, Nafplion, Greece, 2009, pp. 1181-1188.

[40] M. L. Tasker, P. H. Jones, T. Dixon, and B. F. Blake, "Counting seabirds at sea from ships: A review of methods employed and a suggestion for a standardized approach," The Auk, vol. 101, pp. 567-577, 1984.

[41] Z. D. Deng et al., "200 kHz commercial sonar systems generate lower frequency side lobes audible to some marine mammals," PLOS ONE, vol. 9,2014

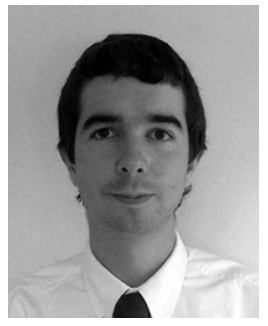

Benjamin J. Williamson received the B.Eng. degree (Hons.) in electrical and electronic engineering, in 2006, and the M.Sc. degree (with Distinction) in mechatronics, in 2007, both from the University of Bath, Bath, U.K. He received the Ph.D. degree from the University of Bath, in 2013, with his dissertation focused on novel hybrid-ROV/AUVs for habitat mapping of kelp beds using multibeam sonar and video in near-shore environments.

$\mathrm{He}$ is currently a Research Fellow at the University of Aberdeen, Aberdeen, U.K., working on the FLOWBEC Project, which investigates the environmental and ecological effects of wave and tidal energy devices. His research interests include AUV development, instrument integration, and algorithm development for sonar processing and target tracking.

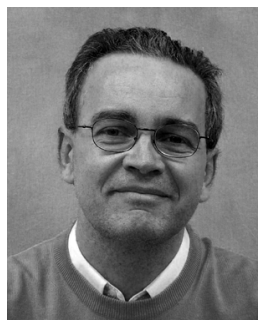

Philippe Blondel received the DEUG-A degree in physics from the University of Rouen, Mont-Saint-Aignan, France, in 1985, the Maîtrise degree in physics from the University of Paris-XI, Orsay, France, in 1987, and the Ph.D degree in physics and remote sensing from the University of Paris-VII, Paris, France, in 1992.

He worked at the University of Washington on sonar imaging at mid-ocean ridges as a Lavoisier Fellow, carrying on this work as a NERC Fellow at the Institute of Oceanographic Sciences, Deacon Laboratory, and the Southampton Oceanography Centre (UK). He moved to the University of Bath in 1999, where he is now Senior Lecturer in Physics and Deputy Director of the Centre for Space, Atmosphere, and Ocean Science. He has written several research textbooks including the "Handbook of Sidescan Sonar" (2009). His research interests include acoustic imaging of marine habitats, underwater noise and anthropogenic impacts, and acoustic monitoring of Arctic processes.

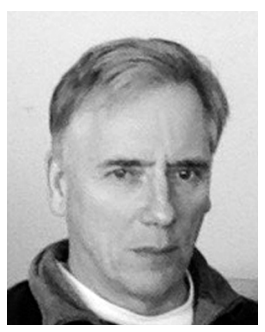

Eric Armstrong has worked in acoustics since 1978, at the Marine Laboratory in Aberdeen. He took part in the early experiments to determine fish target strengths. He provides acoustic/computer expertise on a wide range of acoustic equipment for the Laboratory and a number of other institutes, and has developed control systems for autonomous acoustic instruments.

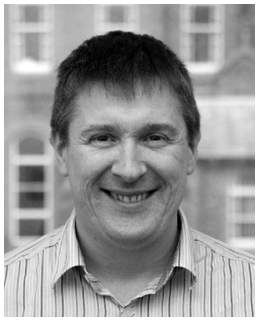

Paul S. Bell received the B.Sc. degree (Hons.) in physics and electronics from the School of Physics and Astronomy, University of St. Andrews, Scotland, U.K., in 1992, and the Ph.D. degree from the School of Ocean Sciences, University of Wales, Bangor, U.K., in 2005, with a dissertation on the remote determination of bathymetric changes using ground-based radar.

Since 1992, he has been with the National Oceanography Centre (previously known as the Proudman Oceanographic Laboratory), Liverpool, U.K., developing a variety of acoustic and radar techniques to study flow and sediment dynamics at coastal sites. He is currently working on the use of ground and vessel based marine radar to map bathymetry, currents, and other hydrodynamic properties at coastal sites.

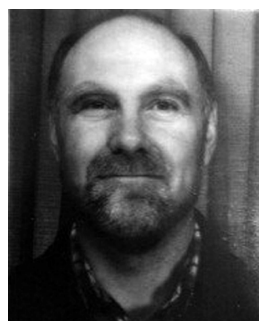

Chris Hall received the B.A. degree (Hons.) in electrical and electronic engineering, in 1987, from the Open University, Buckinghamshire, U.K.

Initially, he was involved in the development of biological monitors and subsea instrumentation. $\mathrm{He}$ is now the Group Leader of Engineering Services at Marine Scotland Science, Marine Laboratory in Aberdeen where he leads a team of specialist electronic and mechanical engineers in the design, development, and construction of a range of subsea scientific equipment, including novel plankton and environmental samplers, subsea instrumentation platforms, and underwater video and photographic observation systems. His research interests include subsea sensors, underwater observation, and ship-board data acquisition systems.

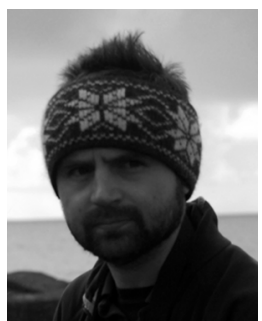

James J. Waggitt received the first class B.Sc. degree in marine biology and coastal ecology, in 2009, and the MRes degree with distinction in marine biology, 2010, from the University of Plymouth, Plymouth, U.K. He has been working toward the Ph.D degree in marine ecology at the University of Aberdeen, Aberdeen, U.K., since 2011.

His research focusses on the behavioral and environmental factors determining the foraging distribution of seabirds. This research has included the combination of biologging, observational surveys, and hydrodynamic model data to test hypothesis-driven questions concerning when and where foraging seabirds are found.

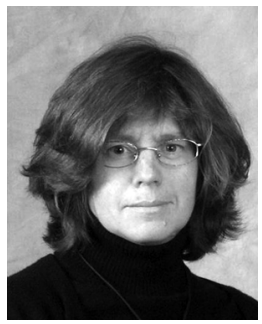

Beth E. Scott received the B.Sc. degree in marine ecology from Simon Fraser University, Burnaby, BC, Canada, in 1984. She received the M.Sc. degree in fisheries oceanography from the University of British Columbia, Vancouver, BC, Canada, in 1990. After working as a Research Fellow for FRS Marine Lab, she received the Ph.D. degree from the University of Aberdeen, Aberdeen, U.K., in 2003, which focused on creating individual based models (IBMs) for commercial fish species.

She is now a Senior Lecturer at the University of Aberdeen where she conducts multidisciplinary research using expertise in marine ecology, oceanography, and fisheries. Her research identifies general rules in biophysical oceanographic processes that lead to the creation of hotspots of predator-prey activity. 